Prepared in cooperation with East Contra Costa County Habitat Conservancy Science and Research Grant Program, East Bay Regional Parks District, Save Mount Diablo's Mary Bowerman Science and Research Grant Program, and NextEra Energy

\title{
Distribution and Abundance of Aquila chrysaetos (Golden Eagles) in the East Contra Costa County Habitat Conservation Plan/Natural Community Conservation Plan Area, California
}

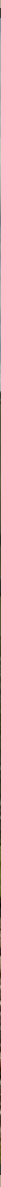

Open File-Report 2020-1107

U.S. Department of the Interior

U.S. Geological Survey 
Cover: View of Round Valley, East Contra Costa County Habitat Conservation Plan/ Natural Community Conservation Plan Area, California. Photograph by Patrick Kolar, U.S. Geological Survey, 2016. 


\section{Distribution and Abundance of Aquila chrysaetos (Golden Eagles) in the East Contra Costa County Habitat Conservation Plan/Natural Community Conservation Plan Area, California}

By J. David Wiens, Patrick S. Kolar, and Douglas A. Bell

Prepared in cooperation with East Contra Costa County Habitat Conservancy Science and Research Grant Program, East Bay Regional Parks District, Save Mount Diablo's Mary

Bowerman Science and Research Grant Program, and NextEra Energy

Open-File Report 2020-1107 


\section{U.S. Department of the Interior DAVID BERNHARDT, Secretary}

\section{U.S. Geological Survey \\ James Reilly II, Director}

U.S. Geological Survey, Reston, Virginia: 2020

For more information on the USGS-the Federal source for science about the Earth, its natural and living resources, natural hazards, and the environment-visit https://www.usgs.gov/ or call 1-888-ASK-USGS (1-888-275-8747).

For an overview of USGS information products, including maps, imagery, and publications, visit https:/store.usgs.gov.

Any use of trade, firm, or product names is for descriptive purposes only and does not imply endorsement by the U.S. Government.

Although this information product, for the most part, is in the public domain, it also may contain copyrighted materials as noted in the text. Permission to reproduce copyrighted items must be secured from the copyright owner.

Suggested citation:

Wiens, J.D., Kolar, P.S., and Bell, D.A., 2020, Distribution and abundance of Aquila chrysaetos (golden eagles) in East Contra Costa County Habitat Conservation Plan/Natural Community Conservation Plan area, California: U.S. Geological Survey Open-File Report 2020-1107, 11 p., https://doi.org/10.3133/ofr20201107.

ISSN 2331-1258 (online) 


\section{Contents}

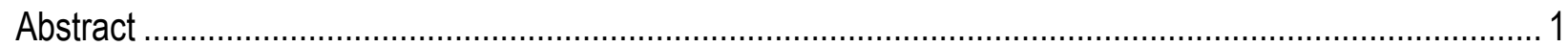

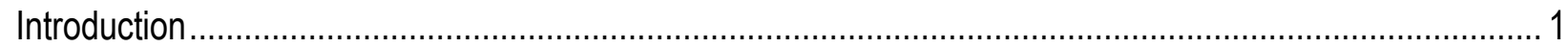

Study Area

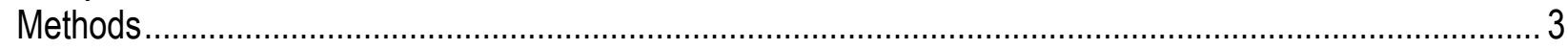

Golden Eagle Surveys .............................................................................................................. 3

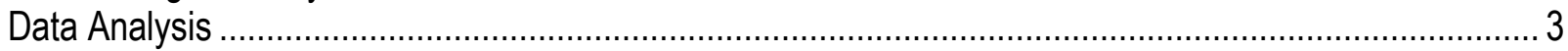

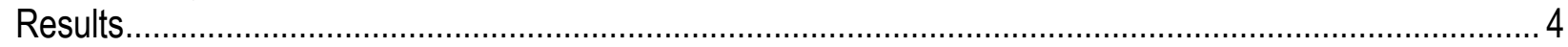

Site Occupancy and Abundance of Golden Eagles..................................................................... 4

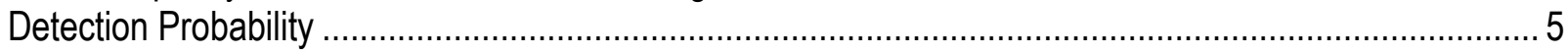

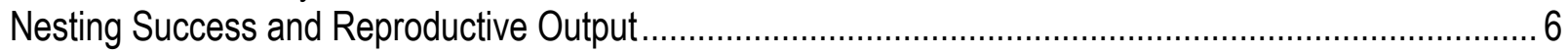

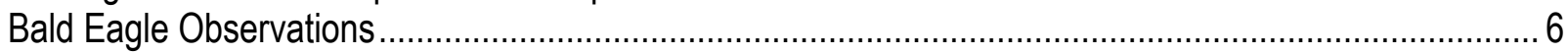

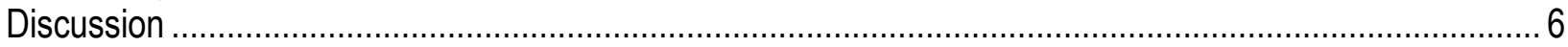

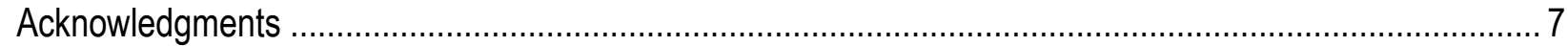

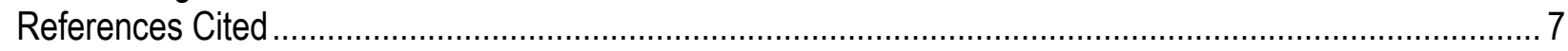

Appendix 1. Ranking of Candidate Occupancy and Abundance Models ..................................................... 11

\section{Figures}

1. Distribution of territorial pairs of golden eagles and survey sites in the East Contra Costa County Habitat Conservation Plan/Natural Community Conservation Plan (HCP/NCCP) inventory area, California, 2019

2. Probability of detecting 1 or more territorial pairs of golden eagles decreased with survey date (January 1-July 24) in the East Contra Costa County Habitat Conservation Plan/Natural Community Conservation Plan area, California, 2019

\section{Table}

1. Parameter estimates from the best models used to characterize site occupancy and abundance of territorial pairs of golden eagles in the East Contra Costa County Habitat Conservation Plan/Natural Community Conservation Plan Inventory area, California, 2019. 


\section{Conversion Factors}

International System of Units to U.S. customary units

\begin{tabular}{|c|c|c|}
\hline \multirow{2}{*}{\multicolumn{3}{|c|}{$\begin{array}{r}\text { By } \\
\text { Length }\end{array}$}} \\
\hline & & \\
\hline kilometer $(\mathrm{km})$ & 0.6214 & mile (mi) \\
\hline \multicolumn{3}{|c|}{ Area } \\
\hline $\begin{array}{l}\text { square kilometer }\left(\mathrm{km}^{2}\right) \\
\text { square kilometer }\left(\mathrm{km}^{2}\right)\end{array}$ & $\begin{array}{c}247.1 \\
0.3861\end{array}$ & $\begin{array}{l}\text { acre } \\
\text { square mile }\left(\mathrm{mi}^{2}\right)\end{array}$ \\
\hline
\end{tabular}

\section{Abbreviations}

$\mathrm{Cl}$

confidence interval

SE standard error

HCP/NCCP East Contra Costa County Habitat Conservation Plan/Natural Community Conservation Plan 


\title{
Distribution and Abundance of Aquila chrysaetos (Golden Eagles) in the East Contra Costa County Habitat Conservation Plan/Natural Community Conservation Plan Area, California
}

\author{
By J. David Wiens ${ }^{1}$, Patrick S. Kolar ${ }^{1}$, and Douglas A. Bell ${ }^{2}$
}

\begin{abstract}
The East Contra Costa County Habitat Conservation Plan/Natural Community Conservation Plan (HCP/NCCP) Preserve System was designed to protect and enhance ecological diversity and function in eastern Contra Costa County, California. Aquila chrysaetos (golden eagle) is a special-status species expected to benefit from biological goals of the HCP/NCCP. As part of a broader study, we estimated site-occupancy, abundance, and reproduction of golden eagles in the HCP/NCCP inventory area in 2019. We completed 99 surveys and recorded a total of 50 detections of territorial pairs of eagles at 20 (67 percent) of 30 sites (13.9-square-kilometer $\left[\mathrm{km}^{2}\right]$ plots). Detection probability of territorial pairs was highest in January and February $(\geq 0.75)$ and lowest in mid-June to late July $(<0.50)$. After correcting for imperfect detection, the expected probability of site-occupancy was 0.69 (standard error [SE] $=$ 0.09 ), and mean expected abundance was 0.76 pairs per site $(\mathrm{SE}=0.16$ ), or 27.4 pairs per 500 $\mathrm{km}^{2}$. We found evidence of successful nesting ( $\geq 1$ young fledged) for 3 (14 percent) of 22 pairs of eagles monitored in 2019. Our study design and baseline results should be useful for future monitoring and conservation of golden eagles in the HCP/NCCP area.
\end{abstract}

\section{Introduction}

The East Contra Costa County Habitat Conservation Plan/Natural Community Conservation Plan (HCP/NCCP; hereinafter, Plan) provides a framework to protect and enhance ecological diversity in the rapidly urbanizing region of eastern Contra Costa County, California (Jones and Stokes, 2006). The Plan provides comprehensive species, wetlands, and ecosystem conservation and is intended to contribute to the recovery of sensitive and endangered species. The Aquila chrysaetos (golden eagle) is a special-status species expected to benefit from biological goals of the Plan in grassland and oak-woodland habitats. Specifically, the $\mathrm{HCP} / \mathrm{NCCP}$ is intended to "maintain or increase population size and distribution of golden eagles in the Plan area" (Jones and Stokes, table 5-1). Despite the importance of golden eagles to the biological objectives of the Plan, information on this species in the Plan area is limited (see Hunt 2002; Hunt and Hunt, 2013; H.T. Harvey and Associates, 2018).

\footnotetext{
${ }^{1}$ U.S. Geological Survey

${ }^{2}$ East Bay Regional Parks District
} 
In 2019, we completed a comprehensive survey of golden eagles in the Plan area. Surveys were completed as part of a larger, concurrent study on population ecology of golden eagles in the vicinity of the Altamont Pass Wind Resource Area (Hunt and others, 2017; Wiens and others, 2015,2018). Our goals were to (1) build upon our existing study design to complete site-occupancy surveys of golden eagles throughout the entire Plan area; and (2) provide baseline estimates of distribution, abundance, and reproduction of golden eagles.

\section{Study Area}

The 704-km ${ }^{2} \mathrm{HCP} / \mathrm{NCCP}$ inventory area is located in eastern Contra Costa County, California (fig. 1). This area was delineated based on a combination of political, ecological, and hydrologic factors (Jones and Stokes, 2006). The northern and eastern parts of the Plan area are dominated by developed, urban, and agricultural lands, whereas the western and southern parts are mostly grassland with widely scattered stands of Quercus spp. (oak), Eucalyptus spp. (eucalyptus), and conifer trees (fig. 1). The HCP/NCCP inventory area is located in the northeastern part of the larger Diablo Range golden eagle study area (fig. 1). This broader study used a random census-plot design to monitor golden eagles during 2014-19 (for details, see Wiens and others, 2015, 2018). The Altamont Pass Wind Resource Area overlaps with the southern boundary of the HCP/NCCP inventory area.

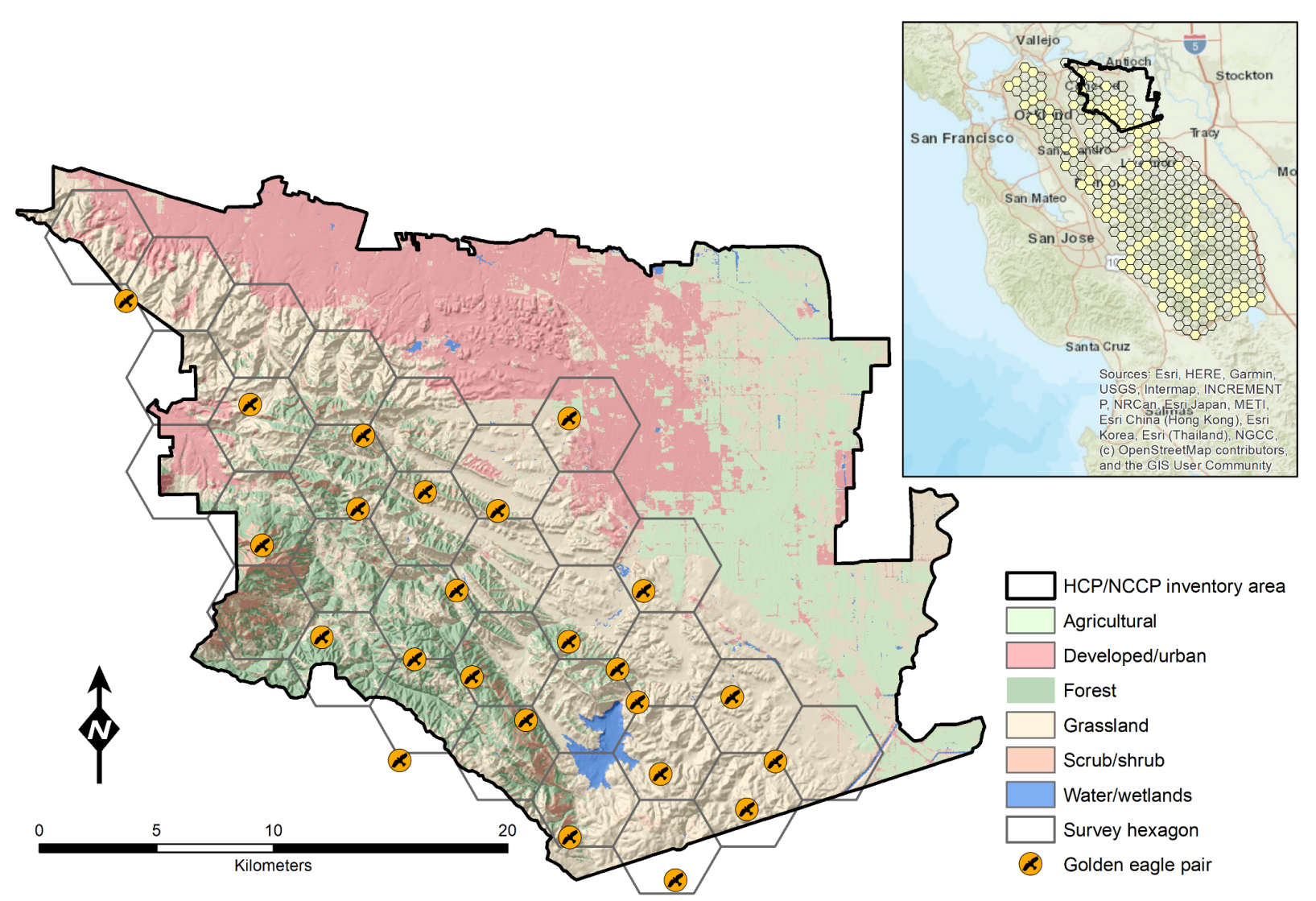

Figure 1. Distribution of territorial pairs of golden eagles and survey sites (13.9-square-kilometer hexagons) in the East Contra Costa County Habitat Conservation Plan/Natural Community Conservation Plan (HCP/NCCP) inventory area, California, 2019. Inset shows the location of the inventory area relative to sites monitored (highlighted hexagons) in the broader northern Diablo Range golden eagle study area. 


\section{Methods}

\section{Golden Eagle Surveys}

Areas targeted for repeated surveys of golden eagles were based on a grid of 30 equalsized $\left(13.9 \mathrm{~km}^{2}\right)$ hexagonal cells overlaid on the Plan area (total area surveyed $=443.2 \mathrm{~km}^{2}$; fig. 1). We excluded densely populated and agricultural landscapes from our surveys because previous studies show that golden eagles rarely used these landscapes (Hunt, 2002; Hunt and others, 2017). The size of each survey hexagon corresponded to the estimated mean territory size of golden eagles (Wiens and others, 2015, 2018). Thus, under our sampling design a "site" was defined as a $13.9-\mathrm{km}^{2}$ area that had the potential to be occupied by 1 or more $(\geq 1)$ territorial pair of golden eagles during the breeding season. We modified survey protocols developed by Driscoll (2010) and Pagel and others (2010) to survey golden eagles. We partitioned surveys within years based on approximate transition dates for stages in the breeding cycle for eagles in our study area (Hunt, 2002): (1) courtship (December 15-February 28), (2) incubation (March 1April 30), (3) nestling (May 1-June 15), and (4) the fledging period (June 16-July 30). Whenever possible, we classified all eagles as juveniles, subadults, or adults based on visible plumage characteristics (Bloom and Clark, 2001; Kolar and Wiens, 2017). Further details on our survey protocols are provided in Wiens and others $(2015,2018)$.

A sample site was considered to be occupied by a territorial pair of eagles if we observed (1) a male and female copulating, undulating, perching together, or attacking intruders; or (2) an incubating eagle in a nest, young nestlings in a nest, or a female observed with a brood patch. We attributed detections of territorial pairs to sample sites by mapping activity centers of pair observations (a used nest; locations of fledglings; or focal area of copulations, territorial displays, and perches) (Wiens and others, 2018). We surveyed sites with pair detections during mid-June to late July to determine the number of young fledged after most nestlings were more than 80 percent of average fledging age (about 56 days old; Driscoll, 2010). A site was accorded successful reproduction if $\geq 1$ nestlings of this age or fledglings were observed (Steenhof and Newton, 2007). During surveys we also recorded observations of Haliaeetus leucocephalus (bald eagle).

\section{Data Analysis}

We estimated site occupancy $(\psi)$, abundance $(\lambda)$, and detection probability $(p)$ for territorial pairs of golden eagles with the "unmarked" package in R, version 3.5.0 (Fiske and Chandler, 2011; R Core Team, 2017). We estimated occupancy using a likelihood-based method (MacKenzie and others, 2002) and abundance using $N$-mixture models (Royle, 2004; Fiske and Chandler, 2011). For both data types, we used an information-theoretic approach (Burnham and Anderson, 2002) to rank competing sets of models representing different effects of primary land cover types or topographic conditions on the distribution of eagles. We used the Coastal Change Analysis Program land cover map of the National Oceanic and Atmospheric Administration to calculate the proportion of developed/urban, forest, grassland, and scrub/shrub cover types in each sample site (National Oceanic and Atmospheric Administration, 2010; fig. 1). We evaluated the effects of landscape topography on eagles by calculating the mean terrain ruggedness index for each site, calculated as the square root of the sum of the squared differences between the elevation in a cell and the elevation of its neighboring cells (Riley and others, 1999; Evans and others, 2014). 
We used the $N$-mixture model to estimate abundance ( $\lambda$, the mean number of territorial pairs per site), which assumes that (1) there is within-plot closure during surveys across the breeding season, and (2) detection histories among sample sites are independent (Nichols and others, 2009; Barker and others, 2018). Our study design minimized the likelihood of violating of these assumptions, but our sample sites were not centered on actual territory locations. As a consequence, we interpreted $\lambda$ as the mean number of breeding pairs with territories (defended areas) overlapping a focal survey site. Counts of territorial pairs during surveys were modeled using a Poisson distribution because preliminary analyses showed that this specification outperformed zero-inflated or negative binomial options. We summed site-specific estimates of mean abundance to yield total expected abundance of territorial pairs and used a parametric bootstrap approach to calculate associated 95-percent confidence intervals (Fiske and Chandler, 2011). We also estimated density of territorial pairs based on pair detections and mapped locations of activity centers. This method was analogous to territory spot-mapping techniques often used to assess model-based methods of density estimation (Bibby and others, 2000; Chandler and others, 2011). When possible, we also mapped activity centers of territorial pairs in areas adjacent to our focal sample sites. This helped us ensure that counts of eagle pairs in the Plan area were accurate and that pairs were not double-counted.

For occupancy and abundance data, we included the day of the survey season on which each site was surveyed (day $0=$ January 1 ) as a covariate to account for within-season variation in detection $(p)$ of eagle pairs. We assessed goodness of fit of occupancy models using methods outlined by MacKenzie and Bailey (2004). We assessed fit of $N$-mixture models using a parametric bootstrap approach and the Pearson chi-square test statistic (Chandler and others, 2011). In both cases, we bootstrapped model estimates 500 times to obtain $P$-values (that is, evidence against the null hypothesis of no lack of model fit) for our most highly parameterized models. We also estimated a dispersion parameter $(\hat{c})$ as the ratio of the observed fit of the chisquare test statistic to the mean of the simulated distribution of the test statistic.

\section{Results}

\section{Site Occupancy and Abundance of Golden Eagles}

We searched 30 of 32 hexagon survey sites overlapping the HCP/NCCP area up to 4 times each $($ mean $=3.3$ surveys per site) and detected 22 territorial pairs of eagles in 20 (67 percent) of these sites (fig. 1). Based on mapped locations of used nests and activity centers, 2 (10 percent) of the 20 occupied sites were used by two pairs of eagles each. We also documented two additional pairs of eagles with activity centers outside the boundary of the Plan area and our focal survey sites (fig. 1). These additional pairs were observed using areas within the Plan area but were not included in analyses of occupancy and abundance.

Expected estimates of landscape occupancy $(\widehat{\psi})$ and abundance $(\hat{\lambda})$ of territorial pairs of eagles estimated under the best models $\left(\triangle \mathrm{AIC} c=0.00^{3}\right.$; appendix 1$)$ are provided in table 1. Estimated total abundance ( 23 pairs) was similar to the naïve estimate ( 22 pairs) calculated using maximum plot counts and unadjusted for detection probability. We found some support for a negative effect of developed land use on expected site-occupancy $\left(\triangle \mathrm{AIC}_{c}=0.72\right.$; appendix 1$)$, but the precision of this relationship was poor $(\hat{\beta}=-3.67, \mathrm{SE}=2.77)$. Occupancy and abundance

\footnotetext{
${ }^{3}$ Difference between the Akaike's Information Criterion for small sample size $\left(\mathrm{AIC}_{c}\right)$ value of each model and the lowest $\mathrm{AIC}_{c}$ model.
} 
models including landscape and terrain covariates generally outperformed a null model without these effects, but 95-percent confidence intervals of covariate slope coefficients widely overlapped zero, indicating little to no support for these effects in our analyses. We found no strong evidence of lack of fit for occupancy $(P=0.13 ; \hat{c}=1.30)$ or abundance $(P=0.97 ; \hat{c}=$ $0.69)$ models, indicating adequate fit of our survey data to model assumptions.

Table 1. Parameter estimates from the best models used to characterize site occupancy and abundance of territorial pairs of golden eagles in the East Contra Costa County Habitat Conservation Plan/Natural Community Conservation Plan Inventory area, California, 2019.

\begin{tabular}{lccc}
\hline \multicolumn{1}{c}{ Parameter } & Estimate & Standard error & $\begin{array}{c}\text { 95-percent } \\
\text { confidence interval }\end{array}$ \\
\hline Expected site occupancy $(\widehat{\psi})$ & 0.69 & 0.09 & $0.55-0.78$ \\
Expected mean number of pairs per site $(\hat{\lambda})$ & 0.76 & 0.16 & $0.49-1.16$ \\
Expected pair abundance & 23 & 0.11 & $22-29$ \\
\hline
\end{tabular}

\section{Detection Probability}

Detection probability $(p)$ of territorial pairs in the Plan area was negatively associated with survey date $(\hat{\beta}=-0.01, \mathrm{SE}=0.01$, fig. 2 , appendix 1$)$. Detection of pairs was highest during surveys conducted during the courtship phase of the breeding season in January and February ( $\geq 0.75$ ), and lowest during the fledging-dependency period in mid-June to late-July $(<0.50)$. This result was similar in both analyses of occupancy and abundance, and consistent with previous findings in the broader Diablo Range study area (Wiens and others, 2015, 2018).

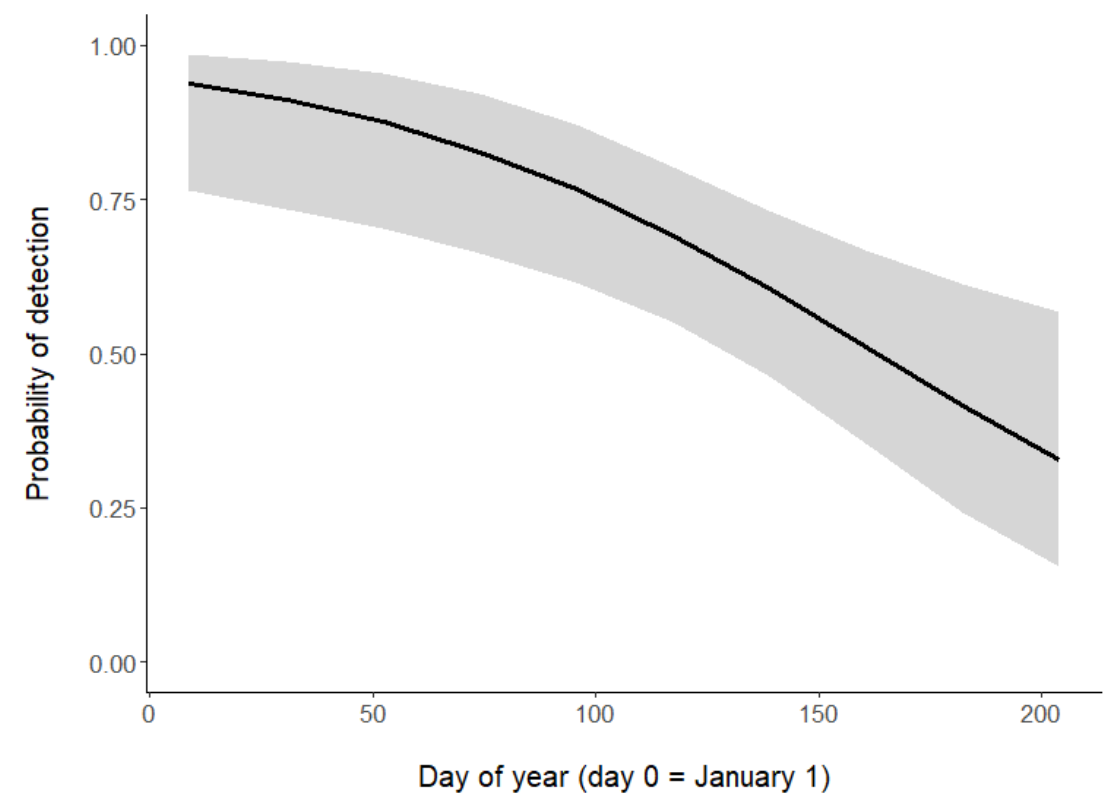

Figure 2. Probability of detecting 1 or more territorial pairs of golden eagles decreased with survey date (January 1-July 24) in the East Contra Costa County Habitat Conservation Plan/Natural Community Conservation Plan area, California, 2019. Solid black line represents expected values estimated under the best model of site occupancy; shading represents 95-percent confidence intervals. 


\section{Nesting Success and Reproductive Output}

We found evidence of successful nesting ( $\geq 1$ young fledged) for 3 (14 percent) of the 22 pairs of eagles monitored in the Plan area in 2019. The mean number of young detected per successful pair was 1.33 ( 2 pairs fledged 1 young each and 1 pair fledged 2 young), and the mean number of young fledged per pair was 0.19 . Three (50 percent) of 6 nesting attempts failed during the early incubation or nestling stages, based on evidence collected at used nests. An additional pair of golden eagles successfully fledged 1 young from a historical nest located on the Concord Naval Weapons Base near the northwest edge of the HCP/NCCP area (fig. 1).

\section{Bald Eagle Observations}

While surveying golden eagles, we identified a previously undocumented pair of bald eagles that nested within the boundary of the Plan area and successfully fledged 2 young. The nest location was approximately $7 \mathrm{~km}$ from the closest body of water.

\section{Discussion}

Our estimate of landscape occupancy by territorial pairs of golden eagles in the Plan area (0.69) in 2019 was similar to estimates reported for the broader northern Diablo Range study area during 2014-16 (0.68-0.79; Wiens and others, 2018). This result indicated that, on average, occurrence and distribution of eagles in the Plan area were comparable to that in the broader study region. Expected occupancy and abundance of eagle pairs in the Plan area was negatively associated with the amount of developed land use at survey sites, but that the precision of this relationship was poor. Indeed, landscape conditions known to strongly influence the distribution of eagles in the broader study region like the amount of open grassland or terrain ruggedness were not well-supported in our analysis in the smaller Plan area. We attribute this inconsistency to the relatively small sample of sites used in our single-season (2019) analysis of the Plan area ( $n=30$ sites) relative to estimates derived from multiple years of surveys in the broader study area $(n=138$ sites; Wiens and others, 2018). Estimated abundance of territorial pairs in the Plan area was 0.76 pairs per $13.9 \mathrm{~km}^{2}$ (or 27.4 pairs per $500 \mathrm{~km}^{2}$ ), which is substantially greater than reported elsewhere for this species (Watson, 2010). Prior to our study, we estimate that historical surveys documented 16 of the 22 pairs we detected in the Plan area (Hunt, 2002; 2017; H.T Harvey and Associates, 2018). We also identified an additional 2 pairs of eagles that were regularly observed using the Plan area but had activity centers (nests) located outside of the Plan area boundary (fig. 1). Thus, in total, we documented 24 pairs of eagles that were associated with, and regularly used, the Plan area, which fell within the 95-percent confidence interval of our $N$-mixture estimate of total expected abundance (22-29 pairs). Naïve and modeled estimates of abundance were similar because of a relatively high probability of detecting pairs during surveys (mean $=0.66$ percent).

Our findings were consistent with previous analyses (Wiens and others, 2018) that highlighted the importance of accounting for imperfect detection in estimates of landscape occupancy and abundance of golden eagles. We found that the detection of pairs decreased over the course of the breeding season. We attribute this pattern to seasonal changes in territorial behaviors (for example, undulation displays) that enhance an observer's ability to detect territorial pairs. This finding emphasized how surveys conducted early in the breeding season (December-February) can optimize detection rates and help provide rapid assessments of site occupancy. 
Occupancy and $N$-mixture models can produce biased estimates when there are few sites, few repeated visits to each site, and few detections; or when heterogeneity in detectability and abundance is not accommodated (Barker and others, 2018, Duarte and others, 2018). Although the number of sites included in our analysis of the Plan area was relatively small, estimates of detection were relatively high across survey periods ( $>50$-percent) and we used a covariate to account for within-season change in detectability of eagles. Moreover, the size of our survey sites matched the biological scale at which territorial pairs of eagles operate within the study region, and modeled estimates of pair abundance aligned well with naïve estimates based on maximum plot counts. As a consequence, we believe that our estimates of site-occupancy and abundance for the Plan area were accurate, robust to analytical assumptions, and repeatable.

Accurate estimates of site-occupancy and abundance provide baseline information essential to assess the effectiveness of conservation strategies in benefitting wildlife like golden eagles. Our findings on the spatial distribution and density of golden eagles in the HCP/NCCP preserve system provide resource managers with an opportunity to prioritize site-specific conservation actions (for example, minimizing disturbance at used nests) that can help minimize the negative impacts of human-caused stressors (for example, fatalities caused by collisions with wind-turbines at the Altamont Pass Wind Resource Area). Because golden eagles are wideranging, long-lived apex predators, local actions that promote survival and productivity can also benefit regional populations and ecosystems.

\section{Acknowledgments}

We thank Christine Carino, Colleen Lenihan, Jeff Smith, Misty Cain, Ben Dudek, Ode Bernstein, and volunteers from the Golden Eagle Monitoring Team of the East Bay Regional Parks District (EBRPD) for their assistance with surveys of golden eagles. We thank the many State, county, and private landowners who provided us with permission to access their lands during our study. Two reviewers provided helpful comments that improved this report.

\section{References Cited}

Barker, R.J., Schofield, M.R., Link, W.A., and Sauer, J.R., 2018, On the reliability of $N$-mixture models for count data: Biometrics, v. 74, no. 1., p. 369-377.

Bibby, C.J., Burgess, N.D., Hill, D.A., and Mustoe, S., 2000, Bird census techniques (2d ed.):

San Diego, California, Academic Press, 302 p.

Burnham, K.P., and Anderson, D.R., 2002, Model selection and multimodel inference-A practical information-theoretic approach (2d ed.): New York, Springer-Verlag.

Bloom, P.H., and Clark, W.S., 2001, Molt and sequence of plumages of golden eagles and a technique for in-hand ageing: North American Bird Bander, v. 26, p. 97-116.

Chandler, R.B., Royle, J.A., and King, D.I., 2011, Inference about density and temporary emigration in unmarked populations: Ecology, v. 92, p. 1429-1435.

Driscoll, D.E., 2010, Protocol for golden eagle occupancy, reproduction, and prey population assessment: Apache Junction, Arizona, American Eagle Research Institute, 55 p.

Duarte, A., Adams, M.J., and Peterson, J.T., 2018, Fitting N-mixture models to count data with unmodeled heterogeneity-Bias, diagnostics, and alternative approaches: Ecological Modelling, v. 374, p. 51-59. 
Evans, J.S., Oakleaf, J., Cushman, S.A., and Theobald, D., 2014, An ArcGIS toolbox for surface gradient and geomorphometric modeling, Version 2.0.0, accessed August 30, 2019, at https://evansmurphy.wixsite.com/evansspatial/.

Fiske, I., and Chandler, R. 2011. Unmarked-An R package for fitting hierarchical models of wildlife occurrence and abundance: Journal of Statistical Software, v. 43, p. 1-23.

Hunt, T.L., and Hunt, W.G., 2013, Golden eagle territory occupancy and reproduction in the vicinity of the Altamont Pass Wind Resource Area-2013 survey results: Report to the East Bay Regional Parks District, Oakland, California.

Hunt, W.G., 2002, Golden eagles in a perilous landscape-Predicting the effects of mitigation for wind turbine blade-strike mortality: Consultant report to California Energy Commission under contract P500-02-043F, Public Interest Energy Research, California Energy Commission, Sacramento.

Hunt, W.G., Wiens, J.D., Law, P.R., Fuller, M.R., Hunt, T.L., Driscoll, D.E., and Jackman, R.E., 2017, Quantifying the demographic cost of human-related mortality to a raptor population: PLOS One, 12(2):e0172232, 22 p. [Also available at https://journals.plos.org/plosone/article/file?id=10.1371/journal.pone.0172232\&type=printable .]

H.T. Harvey and Associates, 2018, Los Vaqueros Reservoir project annual golden eagle monitoring report 2018: Prepared for Contra Costa Water District, Concord, California.

Jones and Stokes, 2006, East Contra Costa County Habitat Conservation Plan and Natural Community Conservation Plan: Prepared by Jones and Stokes, San Jose, California, for East Contra Costa Habitat Conservation Plan Association [variously paged].

Kolar, P.S., and Wiens, J.D., 2017, Distribution, nesting activities, and age-class of territorial pairs of golden eagles at the Altamont Pass Wind Resource Area, California, 2014-16: U.S. Geological Survey Open-File Report 2017-1035, 18 p., https://doi.org/10.3133/ofr20171035.

MacKenzie, D.I., and Bailey, L.L., 2004, Assessing the fit of site-occupancy models: Journal of Agricultural, Biological, and Environmental Statistics, v. 9, p. 300-318.

MacKenzie, D.I., Nichols, J.D., Lachman, G.B., Droege, S., Royle, J.A., and Langtimm, C.A., 2002, Estimating site occupancy rates when detection probabilities are less than one: Ecology, v. 83, p. 2248-2255, https://doi.org/10.1890/0012-9658(2002)083[2248:ESORWD]2.0.CO;2.

National Oceanographic and Atmospheric Administration, 2010, Coastal Change Analysis Program (C-CAP) regional land cover database: Charleston, South Carolina, National Oceanic and Atmospheric Administration Coastal Services Center, accessed March 3, 2013, at https://coast.noaa.gov/digitalcoast/training/ccap-land-cover-classifications.html.

Nichols, J.D., Thomas, L., and Conn, P.B., 2009, Inferences about landbird abundance from count data-Recent advances and future directions, in Thomson, D.L., Cooch, E.G., and Conroy, M.J., eds., Modeling demographic processes in marked populations: New York, Springer, p. 201-235, https://doi.org/10.1007/978-0-387-78151-8_9.

Pagel, J.E., Whittington, D.M., and Allen, G.T., 2010, Interim golden eagle inventory and monitoring protocols; and other recommendations: U.S. Fish and Wildlife Service, Division of Migratory Bird Management, Arlington, Virginia.

R Core Team, 2017, R-A language and environment for statistical computing: Vienna, Austria, R Foundation for Statistical Computing, http://www.R-project.org/.

Royle, J.A., 2004, N-mixture models for estimating population size from spatially replicated counts: Biometrics, v. 60, p. 108-115, https://doi.org/10.1111/j.0006-341X.2004.00142.x. 
Steenhof, K., and Newton, I., 2007, Assessing nesting success and productivity, in Bird, D.M., and Bildstein, K.L., eds., Raptor research and management techniques: Blaine, Washington, Hancock House Publishers, p. 181-192.

Watson, J., 2010, The golden eagle (2d. ed.): London, United Kingdom, T \& AD.

Wiens, J.D., Kolar, P.S., Fuller, M.R., Hunt, W.G., and Hunt, T., 2015, Estimation of occupancy, breeding success, and predicted abundance of golden eagles (Aquila chrysaetos) in the Diablo Range, California, 2014. U.S. Geological Survey Open-File Report 2015-1039, 23 p., http://dx.doi.org/10.3133/ofr20151039.

Wiens, J.D., Kolar, P.S., Hunt, W.G., Hunt, T., Fuller, M.R., and Bell, D.A., 2018, Spatial patterns in occupancy and reproduction of golden eagles during drought - Prospects for conservation in changing environments. The Condor-Ornithological Applications, v. 120, p. $106-124$. 
This page intentionally left blank. 


\section{Appendix 1. Ranking of Candidate Occupancy and Abundance Models}

Table 1.1 Ranking of models used to estimate landscape occupancy $(\psi)$ and abundance $(\lambda)$ of territorial pairs of golden eagles in the East Contra Costa County Habitat Conservation Plan/Natural Community Conservation Plan area, California, 2019.

[Model parameters include: days=survey date (number of days since Jan 1); developed = proportion of survey site with developed landscape; forest $=$ proportion of survey site with forest cover; scrub $=$ proportion of site with scrubshrubland type; grassland $=$ proportion of survey site with grassland; $\mathrm{TRI}=$ terrain ruggedness index; $\mathrm{AIC}_{c}=$ Akaike's Information Criterion for small sample size, $\triangle \mathrm{AIC}_{c}=$ difference between the $\mathrm{AIC}_{c}$ value of each model and the lowest $\mathrm{AIC}_{c}$ model; $\mathrm{AIC}_{c} \mathrm{wt} .=\mathrm{AIC}_{c}$ weight of each model; $K=$ the number of model parameters $]$.

\begin{tabular}{|c|c|c|c|c|}
\hline Models & $K$ & $\mathrm{AlC}_{c}$ & $\Delta \mathrm{AlC}_{c}$ & $\mathrm{AIC}_{c}$ wt. \\
\hline \multicolumn{5}{|c|}{ Occupancy models } \\
\hline$\psi() p.($ days $)$ & 3 & 121.7 & 0.00 & 0.25 \\
\hline$\psi($ developed $) p$ (days) & 4 & 122.4 & 0.72 & 0.17 \\
\hline$\psi() p.\left(\right.$ days $\left.^{2}\right)$ & 4 & 122.9 & 1.24 & 0.13 \\
\hline$\psi($ forest $) p$ (days) & 4 & 123.0 & 1.31 & 0.13 \\
\hline$\psi($ scrubland $) p($ days $)$ & 4 & 124.1 & 2.47 & 0.07 \\
\hline$\psi(\mathrm{TRI}) p($ days $)$ & 4 & 124.3 & 2.67 & 0.07 \\
\hline$\psi($ grassland $) p($ days $)$ & 4 & 124.3 & 2.67 & 0.06 \\
\hline$\psi\left(\right.$ forest $\left.^{2}\right) p($ days $)$ & 5 & 125.1 & 3.42 & 0.04 \\
\hline$\psi\left(\right.$ grass $\left.^{2}\right) p$ (days) & 5 & 126.7 & 5.04 & 0.02 \\
\hline Null model: $\psi() p.()$. & 2 & 127.0 & 5.28 & 0.02 \\
\hline$\psi\left(\right.$ scrubland $\left.^{2}\right) p($ days $)$ & 5 & 127.0 & 5.31 & 0.02 \\
\hline$\psi\left(\right.$ TRI $\left.^{2}\right) p($ days $)$ & 5 & 127.2 & 5.48 & 0.02 \\
\hline \multicolumn{5}{|c|}{ Abundance models } \\
\hline$\lambda() p.($ days $)$ & 3 & 145.14 & 0.00 & 0.35 \\
\hline$\lambda($ developed $) p($ days $)$ & 4 & 146.73 & 1.59 & 0.16 \\
\hline$\lambda($ scrubland) $p$ (days) & 4 & 147.46 & 2.33 & 0.11 \\
\hline$\lambda$ (forest) $p$ (days) & 4 & 147.69 & 2.56 & 0.10 \\
\hline$\lambda$ (grassland) $p$ (days) & 4 & 147.78 & 2.65 & 0.09 \\
\hline$\lambda(\mathrm{TRI}) p$ (days) & 4 & 147.81 & 2.68 & 0.09 \\
\hline$\lambda\left(\right.$ grass $\left.^{2}\right) p($ days $)$ & 5 & 150.21 & 5.07 & 0.03 \\
\hline$\lambda\left(\right.$ forest $\left.^{2}\right) p($ days $)$ & 5 & 150.33 & 5.20 & 0.03 \\
\hline$\lambda\left(\right.$ scrubland $\left.^{2}\right) p($ days $)$ & 5 & 150.54 & 5.40 & 0.02 \\
\hline$\lambda\left(\mathrm{TRI}^{2}\right) p($ days $)$ & 5 & 150.56 & 5.42 & 0.02 \\
\hline Null model: $\lambda() p.()$. & 2 & 154.55 & 9.41 & 0.00 \\
\hline$\lambda() p.\left(\right.$ days $\left.^{2}\right)$ & 4 & 163.87 & 18.74 & 0.00 \\
\hline
\end{tabular}



Publishing support provided by the U.S. Geological Survey Science Publishing Network, Tacoma Publishing Service Center

For more information concerning the research in this report, contact the Director, Forest and Rangeland Ecosystem Science Center U.S. Geological Survey

777 NW 9th St., Suite 400

Corvallis, Oregon 97330

https://www.usgs.gov/centers/fresc/ 
趸 